\title{
Correction to: Mono vs. combo regimens with novel beta-lactam/ beta-lactamase inhibitor combinations for the treatment of infections due to carbapenemase-producing Enterobacterales: insights from the literature
}

\author{
Simone Meini ${ }^{1}$ (1) $\cdot$ Bruno Viaggi ${ }^{2} \cdot$ Carlo Tascini $^{3}$
}

Published online: 19 March 2021

๑) Springer-Verlag GmbH Germany, part of Springer Nature 2021

\section{Correction to: Infection \\ https://doi.org/10.1007/s15010-021-01577-x}

The original version of this article unfortunately contained a mistake. The presentation of Table 1 was incorrect. The corrected Table 1 is given below.

The original article has been corrected.

The original article can be found online at https://doi.org/10.1007/ s15010-021-01577-x.

Simone Meini

simonemeini2@gmail.com

1 Internal Medicine Unit, Felice Lotti Hospital, Pontedera, Azienda USL Toscana Nord-Ovest, Pisa, Italy

2 Department of Anesthesiology, Neuro Intensive Care Unit, Careggi University Hospital, Florence, Italy

3 Infectious Disease Unit, Department of Medicine, University of Udine, Udine, Italy 


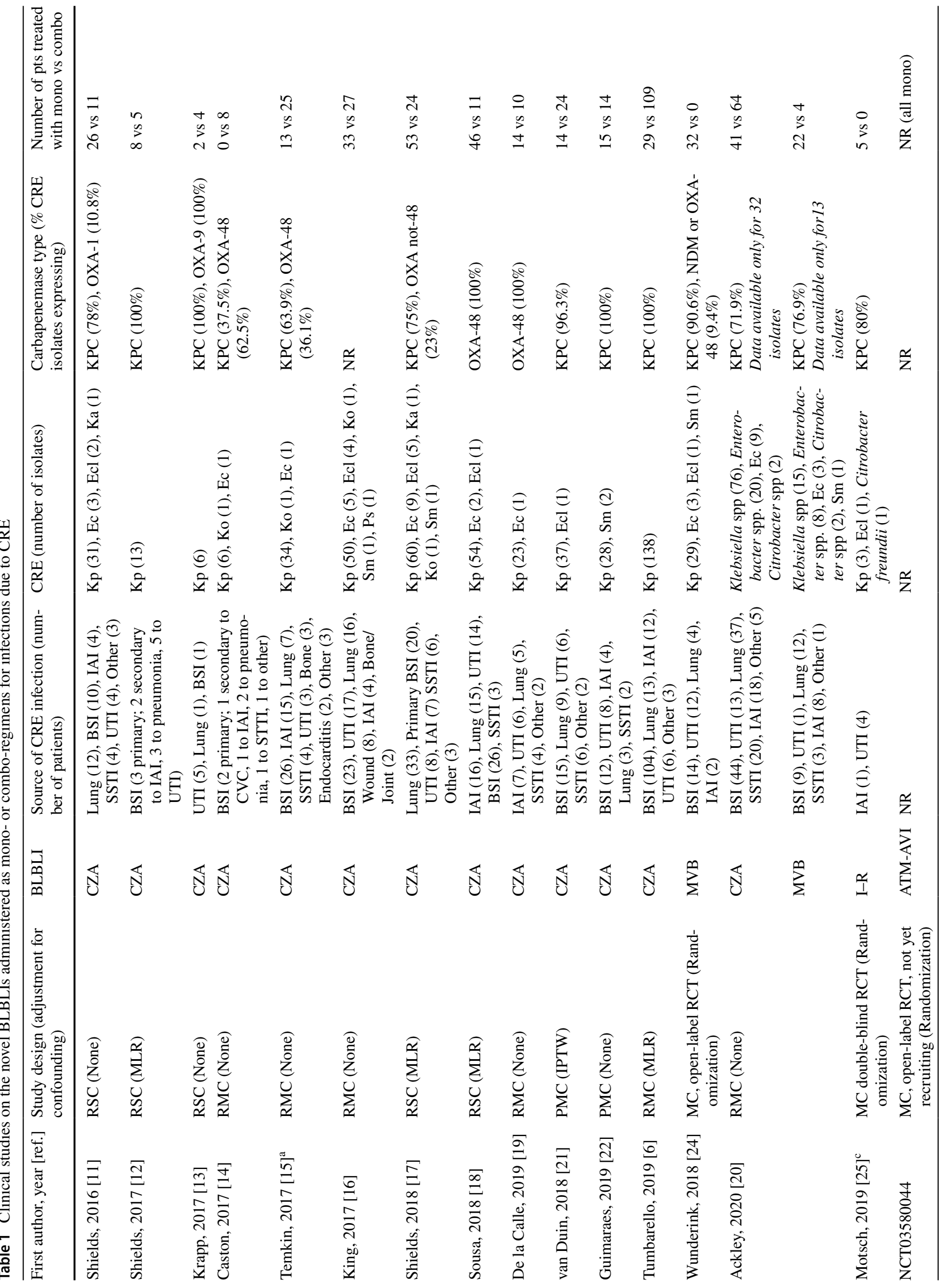




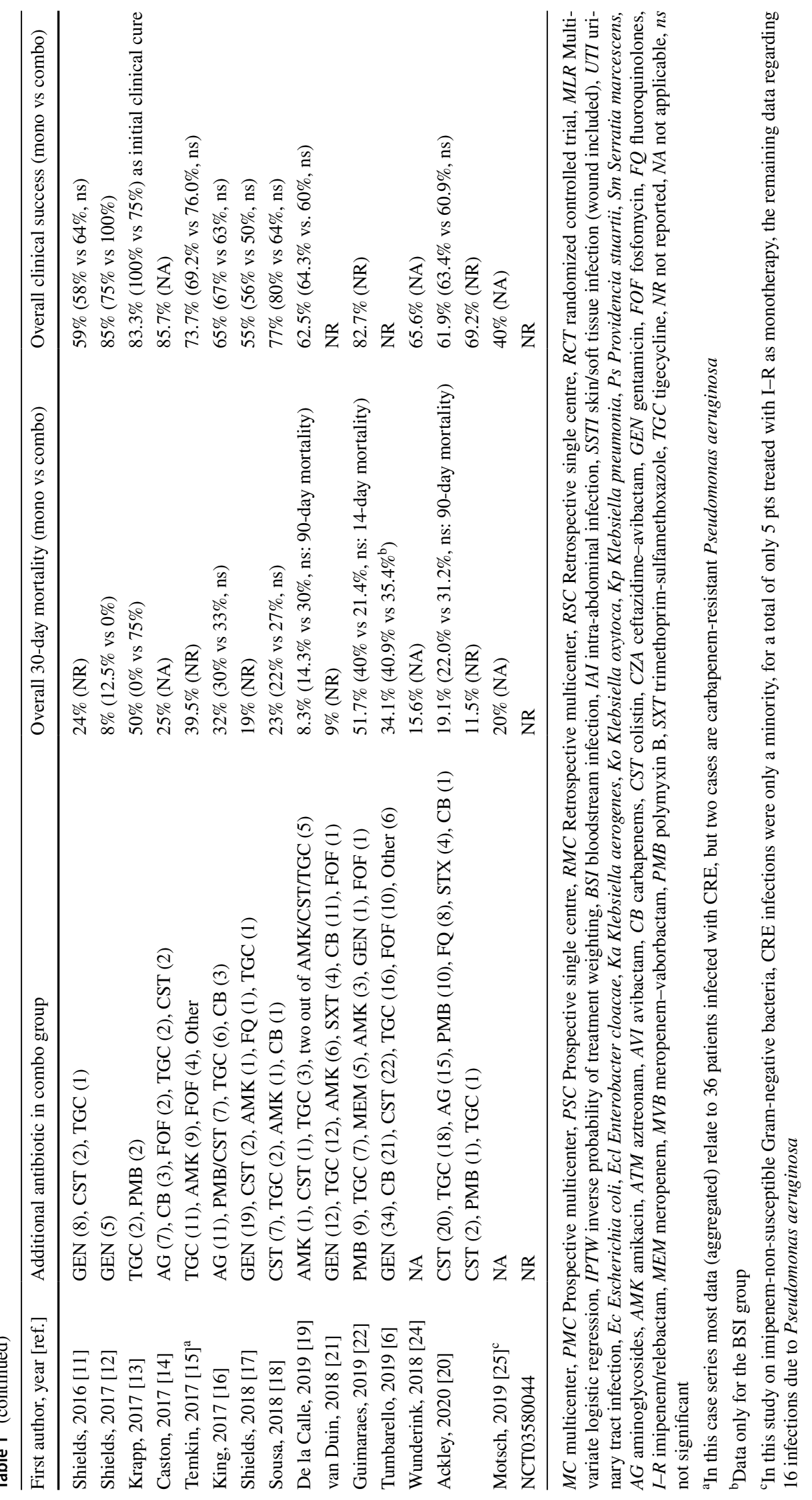

